\author{
International Journal of Innovative Research in \\ Electrical, Electronics, Instrumentation and Control Engineering
}

Vol. 9, Issue 10, October 2021

DOI: 10.17148/IJIREEICE.2021.91019

\title{
POST - BUCKLING BEHAVIOR OF STIFFENED CURVED PANEL USING ARC LENGTH METHOD
}

\author{
Dr. Ganesh $\mathbf{M}^{1}$, Karthick $V^{2}$, Krishna Kumar M $S^{3}$, Naga Pandiyan $R^{4}$, Yuvaraj $R^{5}$ \\ ${ }^{1}$ Associate Professor, Aeronautical Engineering, Hindusthan College of Engineering and Technology, \\ Coimbatore, Tamil Nadu \\ 2,3,4,5 UG - Aeronautical Engineering, Hindusthan College of Engineering and Technology, Coimbatore, Tamil Nadu
}

\begin{abstract}
In this research work, numerical investigations were carried out for the stiffened panel using finite elementbased code. Stiffened panels with various panel radius and stiffener types are considered under uniaxial compression load. The present study is focused on the investigation of the buckling load and ultimate load for the stiffened panel using the load-shortening plots. To predict the critical buckling load and mode shape for the first buckling modes of the stiffened panel have been obtained by the Linear Eigen Value Extraction method. The failure load of the stiffened curved panel after buckling was predicted by using STATIC Riks (arc length) method. Initial geometrical imperfections and nonlinearities of the materials were considered for better results. When the panel radius is increased with constant plate thickness, the buckling load and ultimate load decreases constantly. The stiffened panel with Hat-shape has a higher load carrying capacity compared to the other shapes (I-Shape and J-Shape). The methodology used in this study has good agreement with reference to experimental studies
\end{abstract}

Keywords: Stiffened panel, Buckling load, Ultimate load, Panel radius, Arc length method.

\section{INTRODUCTION}

The stiffened panel is a typical structure in aircraft and space craft in recent years. For an economic reason, there is a great incentive to reduce fuel consumption, which represents a substantial contribution to the weight of the aircraft. The weight plays an important role in aircraft performance. Designers have been increasingly using new design tools to predict the accurate strength of the structures. Due to its high strength to weight, thin-walled structures, especially stiffened panels, are widely used in the aircraft fuselage. Initial geometric imperfections are large for thick composite plates when tested for buckling and analysed for post buckling by A. Karrech et.al (2017) [1]. The energy conjugacy of the second Piola-Kirchhoff and Green-Lagrange strain are used for deriving generalized forces and deformation. R. Bai et.al (2017) [2] monitored and measured the buckling morphology changes using digital fringe projection profilometry (FFP) by applying over the stiffened composite panel during in-plane shearing, which was verified by strain gauge measurement. The influence of damage on the buckling load and on the axial stiffness was evaluated by making a comparison between numerical cases and Experimental tests of the buckling behaviour of a panel in CFRP by A. Castriota et.al (2019) [3]. Y. Feng et. Al (2016) [4] analysed stiffened composite panels with hosted barely visible damage with crater depth data. N. Kharghani and C. Guedes Soares (2020) [5] concluded that a polynomial shape function-based layer wise higher order shear deformation theory is more efficient in calculating the deflection and strains for the very thin to thick laminates in the buckling and post-buckling conditions. Simply supported cylindrical steel panels under in-plane bending stresses were studied by A. D. Martins and N. Silvestre (2020) [6], A semi-analytical procedure is based on an orthotropic model was used by T. Manco et.al (2019) [7] to analyse the post-buckling behaviour of stiffened cylindrically curved steel panels with number of stiffeners and geometry of the stiffeners under uniform uniaxial compression. Y. SU et.al (2019) [8] investigated the structural behaviour of Ti6Al4V titanium alloy stiffened panels under in-plane shear load by experiments and numerical analysis. According to the parametric analysis, the stringer thickness influences the final buckling mode and failure mode, while the stringer height affects the buckling mode transformation. K. L. Tran et.al (2014) [9] applied a uniform longitudinal load on stiffened curved panels and studied its behaviour under linear buckling and ultimate strength. It revealed that both the criteria are subjective by the coupled effects of curvature and stiffening. Y. Ye et.al (2018) [10] used a computational model to study the composite T-stiffened panels with different bonding methods. The model predicted the post buckling behaviour of the stiffeners co-cured, co-bonded, and secondary bonded to the skin. An I- shaped stiffened panel of carbon fibre reinforced polymer (CFRP) composite was studied R. Bai et al. (2018) [11] under compression loads to understand the mechanical behaviour and failure mode using digital fringe projection profilometry 


\section{IJIREEICE}

\section{International Journal of Innovative Research in \\ Electrical, Electronics, Instrumentation and Control Engineering}

Vol. 9, Issue 10, October 2021

\section{DOI: 10.17148/IJIREEICE.2021.91019}

(FFP). The design and fabrication process of the I shaped stiffened CFRP panel was found to be reasonable during the experiment and can be used to study the failure modes. A blade-stiffened panel and a large-scale hat-stiffened panel were systematically investigated by L. Zhao et al. (2019) [12] for post buckling failure processes under uniaxial compression. Computation cases with various damage models were designed and implemented, and the effects of intra- and interlaminar damage, stiffener debonding, and their potential interactions on the post-buckling failure process of the stiffened panel were clarified. A comprehensive parametric study of the behaviour of stiffened plates were done by S. Piculin and P. Može (2021) [13] to demonstrate the benefits obtained from bridge decks with curved plates. The effects of curvature, plate slenderness, size and shape of stiffeners on the ultimate resistance of stiffened curved plates are studied. Carbon fibre reinforced polymer (CFRP) composite panels with secondary bonded blade stiffener are investigated experimentally by N. R. Kolanu et.al (2018) [14] to understand the failure characteristics under stability behaviour under compression. Buckling, post-buckling response and failure characteristics of CFRP panels were captured using various experimental techniques like 3D-digital image correlation (DIC), acoustic emission (AE), strain gaging and infrared thermography. Hashin's failure criteria was used to study the initiation of various failure modes in the critical regions of the stiffened CFRP panel. Finite element numerical models were developed by S. N. Masood et al. (2019) [15] for pristine and impacted panels. The study included inter-laminar and intra-laminar damage initiation, growth models. The study compared all the panels with the investigation of effect of impact damage due to bucking load, post buckling response, collapse load and end-shortening.

\section{METHODOLOGY}

Finite element analysis for composite curved stiffened panels with dimensions of $830 \mathrm{~mm}$ x 850 mm dimensions and various thicknesses was carried out by using finite element-based code Abaqus v6.14. Initially, the critical buckling load and mode shape for the first buckling modes of stiffened panel have been obtained by the Linear Eigen Value Extraction method. Secondly, the initial geometric imperfections compared to the panel thickness (0.1-5\%), have been implemented into Finite Element model for the non-linear analyses. Element Selection plays key role in finite element analysis. Computation time, accuracy of results, required mesh density various with respect to element. Considering these factors, linear and non-linear analysis of composite stiffened panel has been carried out by using shell elements S4 and S4R. S4 is a fully integrated three-dimensional finite membrane strain shell element which has four-node and four integration points and it is suitable for large-strain analysis. Whereas, S4R four-noded, quadrilateral, stress/displacement shell element with reduced integration and large-strain formulation and finite membrane strains, large rotations are taken into account by this element. Therefore, this element is also suitable for non-linear large displacement analysis as $\mathrm{S} 4$ elements. The only difference between these elements is the number of integration points. Using reduced integration, computation of element stiffness can be performed by using lower orders formulation. When reduced integration element is used, fine mesh and distributed loads are required to block hourglass effect. Fully integrated elements do not require hourglass control and give more accurate results with respect to reduced integration elements but computation time of this element is greater by 4 or 5 times than reduced integrated ones.

\subsection{Linear and non-linear Analysis}

Buckling or collapse behaviour can occur in geometrically non-linear problems. In this study, instability analyses have been carried out using various analysis procedures. These are Eigen value buckling prediction (linear perturbation procedure) and Riks method (arc-length).

\subsection{Linear Eigen value extraction method.}

Eigen value buckling prediction is a linear perturbation procedure which provides critical buckling loads and imperfection sensitivity of structures. To determine the Eigen values, a reference load and required boundary conditions have been applied to Finite element model. The magnitude of this load is insignificant since load is scaled by the Eigen values. Eventually, when eigen values obtained from Lanczos analysis are multiplied with the reference load applied to the model, the critical buckling load of the structure at the specified buckling mode is obtained. In this thesis study, critical buckling load of first mode has been taken into consideration since it is the lowest one for composite laminated flat plates but a quite number of buckling modes can be obtained using LANCZOS analysis procedure.

\subsection{Post-buckling Analysis}

An Eigen value analysis does not inform about post-buckled deformation of laminated plate under increasing loading. Therefore, non-linear static analysis is required to investigate post-buckling response of structure. Two methods have been considered in this study to investigate the post-buckling analysis: Riks method and Newton- Raphson method by viscous damping. Newton-Raphson method is prone to fail under load or displacement control for the problems which include highly non-linear behaviour like buckling or collapse. In a classical buckling problem, when the load 


\section{International Journal of Innovative Research in \\ Electrical, Electronics, Instrumentation and Control Engineering}

Vol. 9, Issue 10, October 2021

\section{DOI: $10.17148 /$ IJIREEICE.2021.91019}

reaches the critical buckling point, Newton-Raphson method fails during the transition between primary equilibrium path and secondary equilibrium path. Therefore, Riks Method is offered for unstable and collapse analysis. However, Riks Method is an expensive analysis procedure on account of computation time and convergence rate. Furthermore, many convergence problems are observed during the post-buckling analysis of the stiffened that were carried out by using Riks Method.

\subsection{Physical Model}

The present work involves CAE analysis executed using finite element-based code Abaqus/CAE 6.14-1 software. The composite stiffened curved panel configurations have been designed for various panel radius, plate thickness, stiffener thickness, types of stiffeners, distance between the stiffener and types of cut-outs subjected to uniaxial compression load. Investigation is carried out to establish more resourceful schemes to enhance the buckling and postbuckling behavior of the stiffened panel. The effects of introducing the cut-out between the stiffeners in the stiffened curved panel are studied using Arc length method. The chosen geometry (Reference model for this work is based upon the geometry of (Yuming Mo et al. 2015). Geometry of the reference model is given in Table 1. SR4 is suitable for analyzing thin to moderately-thick shell structures. SR4 can be used for layered applications for modeling composite shells or sandwich construction. The accuracy in modeling composite shells is governed by the first-order sheardeformation theory. The element formulation is based on logarithmic strain and true stress measures. However, the curvature changes within a time increment are assumed to be small.

Table 1: Details of the Reference model and Mechanical properties of CYCOM 977-2 (Source: Shuhua Zhu et al. 2015)

\begin{tabular}{|l|l|}
\hline Feature & $\begin{array}{l}\text { Dimensions } \\
(\mathbf{m m})\end{array}$ \\
\hline Length of the stiffened panel $(\mathrm{a})$ & $\mathbf{8 5 0}$ \\
\hline Width of the stiffened panel $(\mathrm{b})$ & $\mathbf{8 3 0}$ \\
\hline Panel radius $(\mathrm{R})$ & $\mathbf{5 0 0 - 2 0 0 0}$ \\
\hline Thickness of plate $\left(\mathrm{t}_{\mathrm{p}}\right)$ & $\mathbf{1 . 8 5 - 3 . 7}$ \\
\hline Thickness of stiffener $\left(\mathrm{t}_{\mathrm{s}}\right)$ & $\mathbf{1 . 8 5 - 3 . 7}$ \\
\hline Height of the stiffener $\left(\mathrm{h}_{\mathrm{s}}\right)$ & $\mathbf{2 0}$ \\
\hline Rivets Spacing $\left(\mathrm{b}_{\mathrm{r}}\right)$ & $\mathbf{2 5}$ \\
\hline $\begin{array}{l}\text { Distance between the stiffeners } \\
(\text { d) }\end{array}$ & $\mathbf{1 6 6 - 2 7 6 . 7}$ \\
\hline Diameter of circular cut-out $\left(\mathrm{d}_{\mathrm{c}}\right)$ & $\mathbf{1 0 0}$ \\
\hline Side of square cut-out $\left(\mathrm{d}_{\mathrm{s}}\right)$ & $\mathbf{1 0 0}$ \\
\hline
\end{tabular}

\begin{tabular}{|c|c|c|c|}
\hline \multicolumn{2}{|l|}{ Stiffness } & \multicolumn{2}{|c|}{ Strength } \\
\hline $\mathbf{E}_{1}$ & $\begin{array}{l}140.5 \\
\text { GPa }\end{array}$ & $\mathbf{X}_{\mathbf{c}}$ & $\begin{array}{l}1602 \\
\mathrm{MPa}\end{array}$ \\
\hline $\mathbf{E}_{2}$ & 8.54 GPa & $\mathbf{Y}_{\mathbf{c}}$ & $\begin{array}{l}212.8 \\
\text { MPa }\end{array}$ \\
\hline $\begin{array}{l}\mathbf{G}_{12} \\
\mathbf{G}_{13}\end{array}$ & 4.37 GPa & $\mathbf{S}$ & $\begin{array}{l}111.9 \\
\text { MPa }\end{array}$ \\
\hline $\mathbf{G}_{23}$ & $4.2 \mathrm{GPa}$ & & \\
\hline$v_{12}$ & 0.32 & & \\
\hline
\end{tabular}

The material of the stiffened panel is the woven carbon fiber reinforced epoxy composite CYCOM 977-2 (Shuhua Zhu et al. 2015) and its mechanical properties are listed in Table 1. The nominal thickness of each ply is $0.185 \mathrm{~mm}$. The stiffened panel has [45/-45/90/0/90/90/0/90/-45/45] lamination for plate and stiffener.

The boundary conditions considered at the four edges (A, B, C and D) of the stiffened curved panel were clamped as shown in Figure 1. The built-in conditions are applied by restraining all degrees of freedom at B, C and D edges of the finite element model. At the edge A, only the displacement along the Z-direction is allowed and other degrees of freedom are restrained. An incremental compressive load is applied along the Z-direction. Multi-point constraints (MPCs) are an advanced feature that lets the user "connect" different nodes and degrees of freedom together in the analysis. They are often used to simulate a boundary condition effect when regular boundary conditions will not provide the correct behavior.

Table 2: Boundary Conditions of the Model

\begin{tabular}{|l|l|}
\hline Edge & $\begin{array}{l}\text { Restricted Boundary } \\
\text { Conditions }\end{array}$ \\
\hline A & $\mathrm{u}, \mathrm{v}, \theta_{\mathrm{x}}, \theta_{\mathrm{y}}, \theta_{\mathrm{z}}$ \\
\hline B & $\mathrm{u}, \mathrm{v}, \mathrm{w}, \theta_{\mathrm{x}}, \theta_{\mathrm{y}}, \theta_{\mathrm{z}}$ \\
\hline C & $\mathrm{u}, \mathrm{v}, \mathrm{w}, \theta_{\mathrm{x}}, \theta_{\mathrm{y}}, \theta_{\mathrm{z}}$ \\
\hline D & $\mathrm{u}, \mathrm{v}, \mathrm{w}, \theta_{\mathrm{x}}, \theta_{\mathrm{y}}, \theta_{\mathrm{z}}$ \\
\hline
\end{tabular}

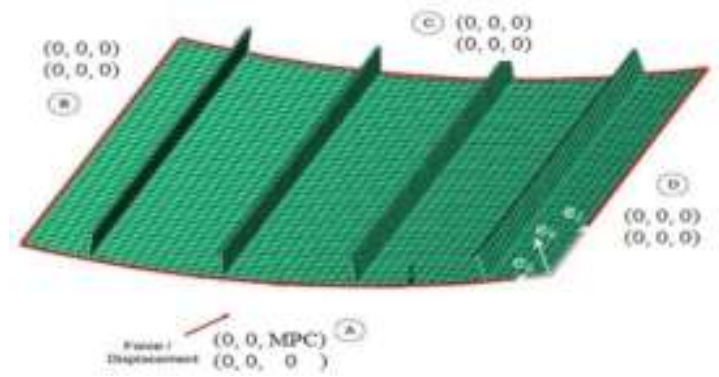

Figure 1: Boundary conditions and meshing of Reference Model (Source: Yuming Mo et al. 2015) 


\section{International Journal of Innovative Research in \\ Electrical, Electronics, Instrumentation and Control Engineering}

Vol. 9, Issue 10, October 2021

\section{DOI: $10.17148 / I J I R E E I C E .2021 .91019$}

The main objective of this research is to study the buckling and post-buckling analysis of the stiffened curved panel. To predict the initial buckling load of the stiffened panel, unit load is given as the starting incremental load for eigen value analysis. Once the initial buckling load is predicted, the Riks method is used to find the ultimate load. The initial buckling load is used as starting load with load increment parameter. Based on the panel radius the panels are named as P1, P2, P3 and $\mathrm{P} 4$ for $500 \mathrm{~mm}, 1000 \mathrm{~mm}, 1500 \mathrm{~mm}$ and $2000 \mathrm{~mm}$ respectively. From the above panel radius best two radiuses were taken into the account.

Table 3: Reference Identification of models

\begin{tabular}{|c|c|c|c|c|c|c|}
\hline \multirow{2}{*}{$\begin{array}{l}\text { Panel radius } \\
\text { (R) } \\
\text { mm }\end{array}$} & \multirow{2}{*}{$\begin{array}{l}\text { Number } \\
\text { of } \\
\text { stiffeners }\end{array}$} & \multirow{2}{*}{$\begin{array}{l}\text { Plate } \\
\text { thickness } \\
\left(\mathbf{t}_{\mathrm{p}}\right) \\
\mathbf{m m}\end{array}$} & \multirow{2}{*}{$\begin{array}{l}\text { Stiffener } \\
\text { thickness } \\
\left(\mathbf{t}_{\mathbf{s}}\right) \\
\mathrm{mm}\end{array}$} & \multicolumn{3}{|c|}{ Panel -ID } \\
\hline & & & & J-shape & I - shape & $\begin{array}{l}\text { Hat } \\
\text { shape }\end{array}$ \\
\hline 1000 & 2 & 1.85 & 1.85 & P2J2 & P2I2 & P2H2 \\
\hline 1500 & 2 & 1.85 & 1.85 & P3J2 & P3I2 & P3H2 \\
\hline
\end{tabular}

\section{RESULTS AND DISCUSSION}

Numerical investigations are carried out to study the buckling and post-buckling behaviour of the various panels as mentioned in Table 3. Various factors which effect the buckling and failure load of the panels are as follows:

- $\quad$ Panel radius $(500-2000 \mathrm{~mm})$

- $\quad$ Type of stiffener (I-, J-, Hat- shape)

To predict the failure load of the various panels, arc length method is used by plotting the load vs displacement curve. The influences of the above-mentioned parameters are detailed in the following sections.

\subsection{Influence of Panel Radius}

The effect of the curvature of the panel is one of the critical factors when designing the aircraft fuselage and wing. The initial buckling load of the panel P1, P2, P3 and P4 are tabulated in the Table 4. The radius of curvature of the panels is limited to the range between $(\mathrm{b} / 2 \pi$ ) to infinity. The post- buckling behaviour of the panel P1, P2, P3 and P4 are shown in the Figures 2, 3, 4 and 5 respectively. The ultimate loads of the panel P1, P2, P3 and P4 are tabulated in the Table 4. The ultimate loads of the panel are 1.5 times of the initial buckling load of the panels.

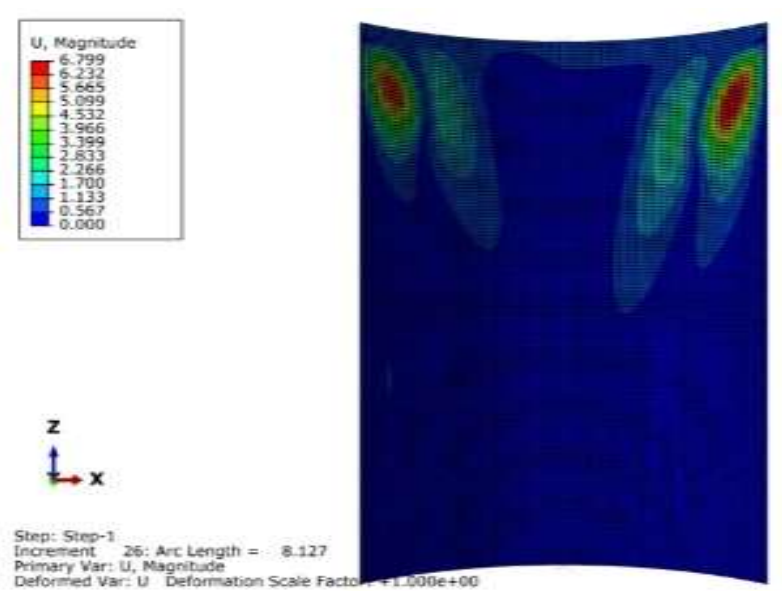

Figure 2: Post- Buckling Behaviour of the panel P1

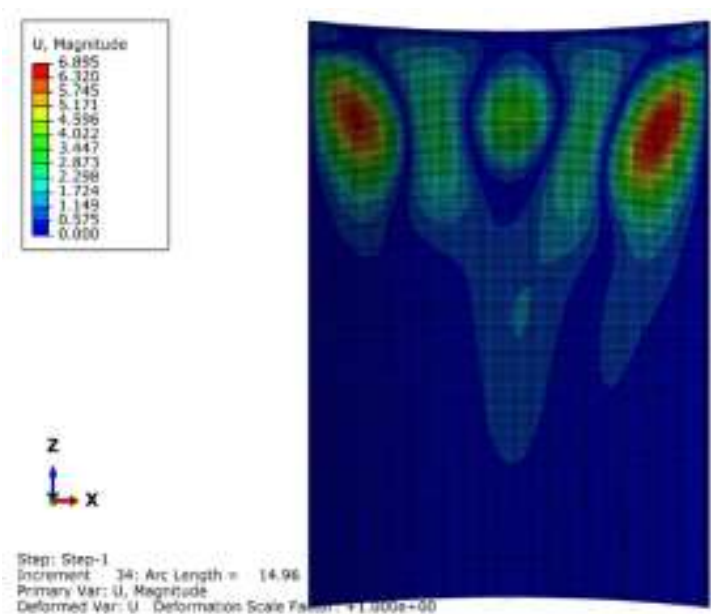

Figure 3: Post- Buckling Behaviour of the panel P2 


\section{International Journal of Innovative Research in Electrical, Electronics, Instrumentation and Control Engineering}

Vol. 9, Issue 10, October 2021

DOI: 10.17148/IJIREEICE.2021.91019
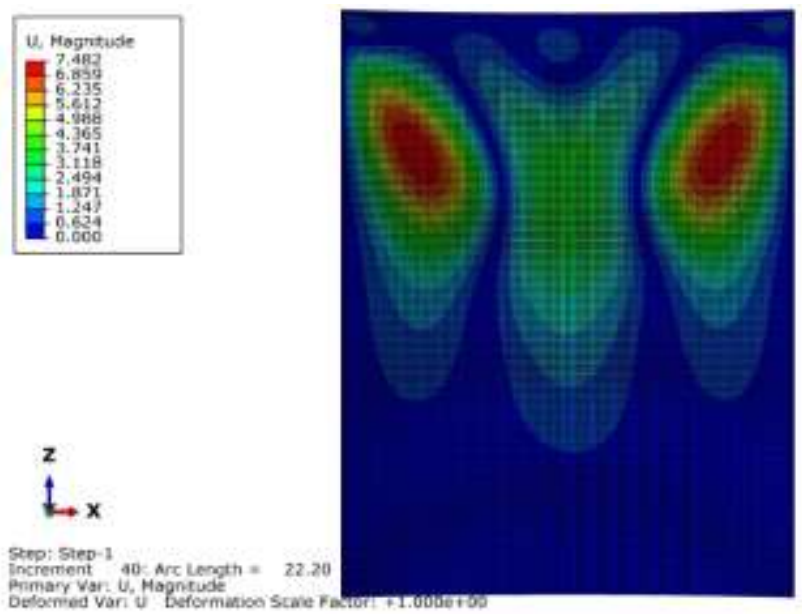

Figure 4: Post- Buckling Behaviour of the panel P3
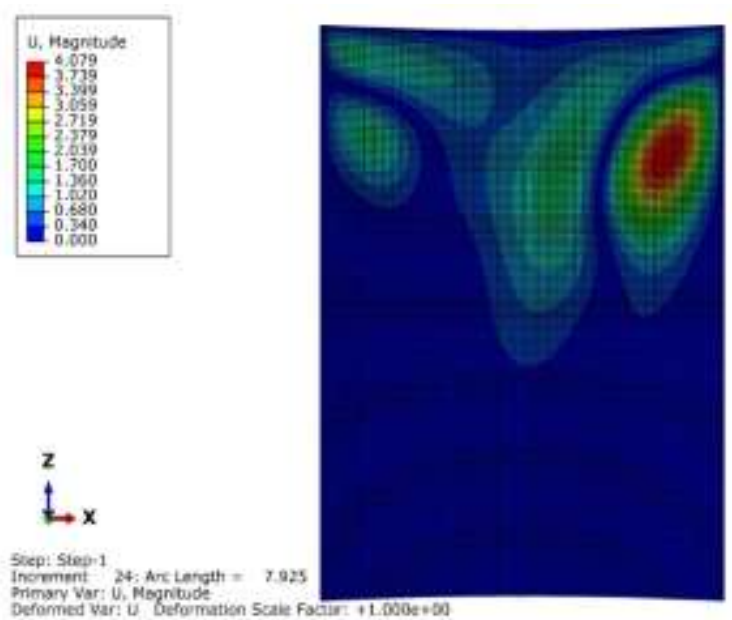

Figure 5: Post- Buckling Behaviour of the panel P4

In Table 4, the initial buckling load and ultimate load of the panel compared for various panel radius. By comparing the initial buckling load and ultimate load of the panels, P1has higher buckling load and ultimate load for lower panel radius and the panel P4 has lower buckling load and ultimate load for higher panel radius.

Table 4: Comparison of the panel with various panel radiuses

\begin{tabular}{|l|l|l|l|}
\hline $\begin{array}{l}\text { PANEL } \\
\text { ID }\end{array}$ & $\begin{array}{l}\text { PANEL } \\
\text { RADIUS } \\
(\mathrm{mm})\end{array}$ & $\begin{array}{l}\text { INITIAL } \\
\text { BUCKLING LOAD } \\
(\mathrm{kN})\end{array}$ & $\begin{array}{l}\text { ULTIMATE } \\
\text { LOAD }(\mathrm{kN})\end{array}$ \\
\hline P1 & 500 & 133.764 & 234.8067 \\
\hline P2 & 1000 & 95.676 & 166.8561 \\
\hline P3 & 1500 & 74.723 & 122.0055 \\
\hline P4 & 2000 & 67.71 & 101.2021 \\
\hline
\end{tabular}

The load-shortening curves of the panel P1, P2, P3 and P4 shown in Figure 6 gives specific behaviour of the pre-buckling and after buckling. For every increase of panel radius of $500 \mathrm{~mm}$ there is an increase of buckling load and ultimate load. The panel P2 and P3 shows better results compare the results by Yuming Mo et al. 2015. In the following section P2 and P3 panel were used for further discussion. The variation of the buckling load and ultimate load concerning different panel radius is very small compared to the other considered parameters.

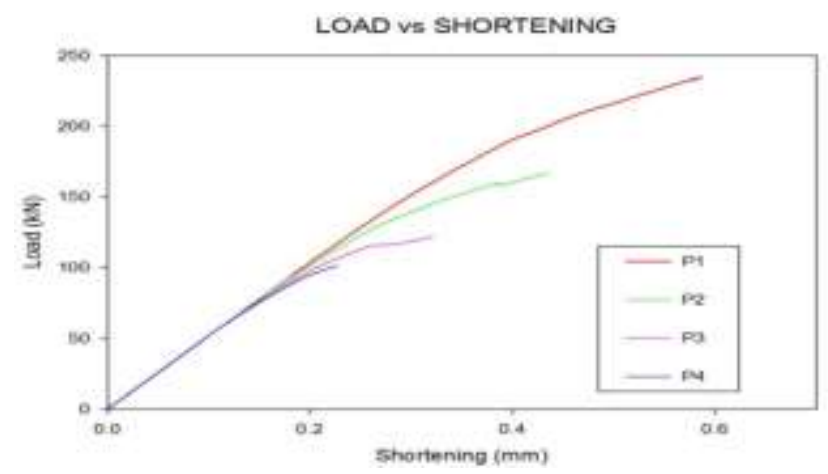

Figure 6: Load-shortening curves of panel P1, P2, P3, and P4

\subsection{Influence of The Type of Stiffener}

The cross-sectional area of the stiffened panel plays a vital role in the stiffened curved panels which increase the buckling strength of the panel. The buckling load and ultimate load of the stiffened panel, with 2- stiffeners in each panel found by arc length method. In this section, thickness of plate and stiffener as $1.85 \mathrm{~mm}$ and the panel radius as $1000 \mathrm{~mm}$ and 1500 $\mathrm{mm}$. The initial buckling loads of the panel without and with stiffener are tabulated in Table 5. The post-buckling behaviours of the panel without stiffener (P2 and P3) were shown in Figures 3 and 4 and panel with the stiffener (P2I2, P2J2, P2H2, P3I2, P3J2, and P3H2) were shown Figures 7 - 12. The ultimate loads of the panel without and with stiffener are tabulated in Table 5. 
International Journal of Innovative Research in

Electrical, Electronics, Instrumentation and Control Engineering

Vol. 9, Issue 10, October 2021

DOI: 10.17148/IJIREEICE.2021.91019
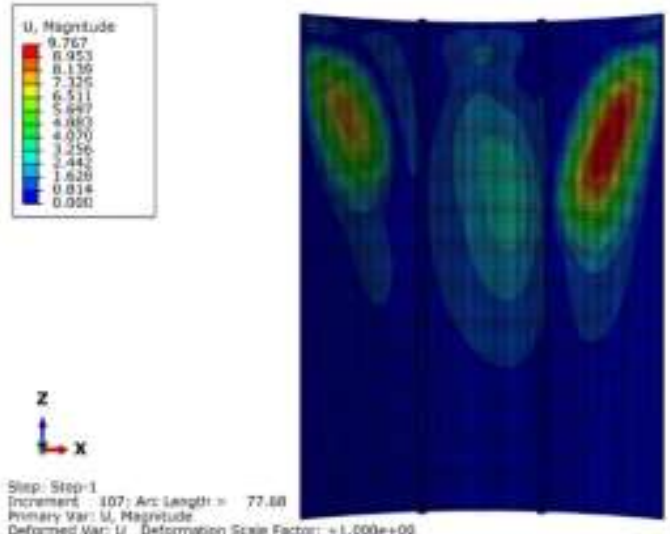

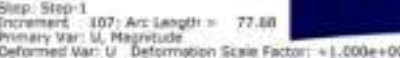

$t_{x}$

Figure 7: Post - Buckling Behaviour of the panel P2I2
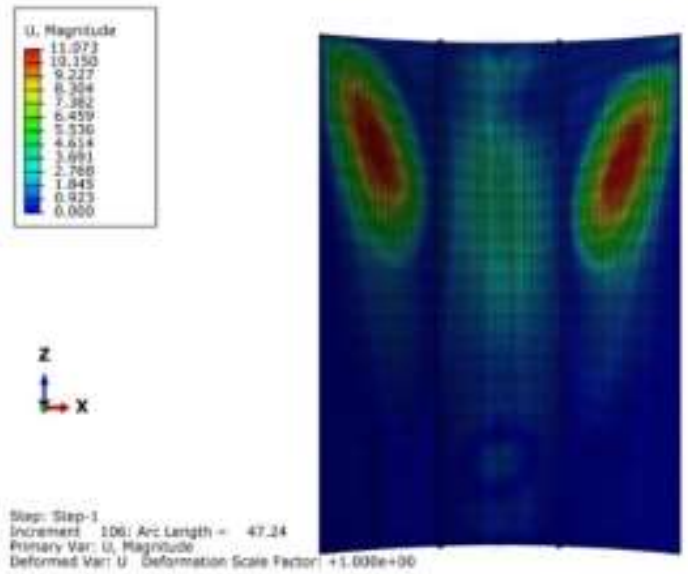

Figure 9: Post - Buckling behaviour of the panel P2H2
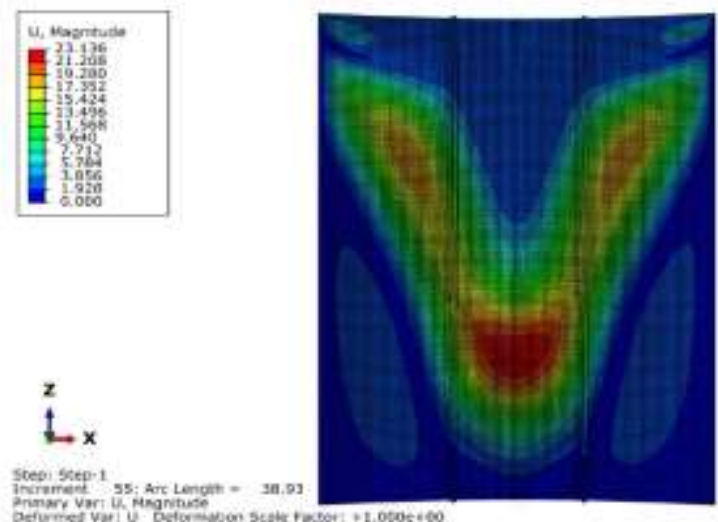

Figure 11: Post - Buckling Behaviour of the panel P3J2
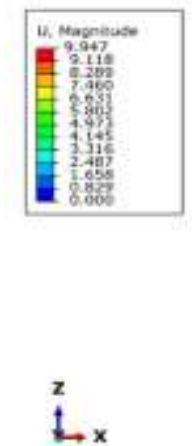

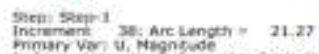

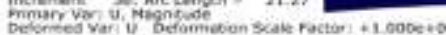

Figure 8: Post - Buckling Behaviour of the panel P2J2
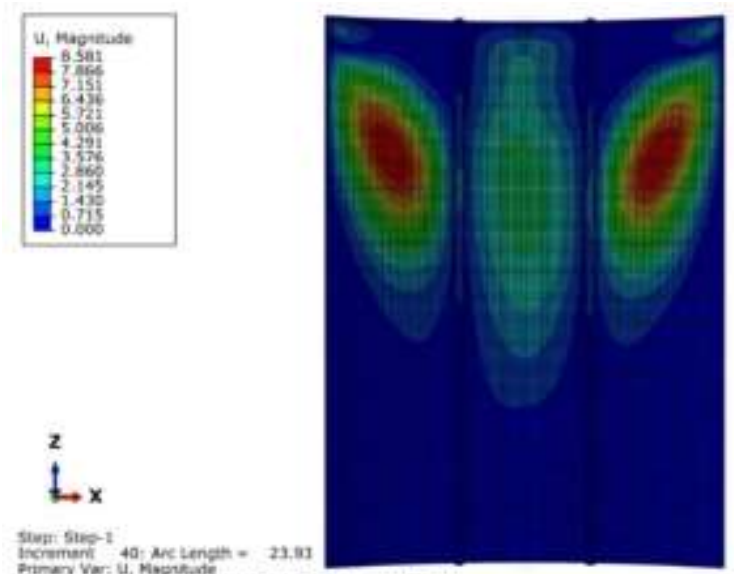

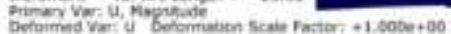

Figure 10: Post - Buckling Behaviour of the panel P3I2
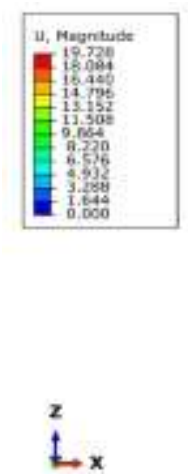

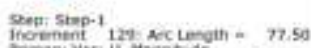

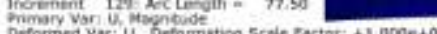

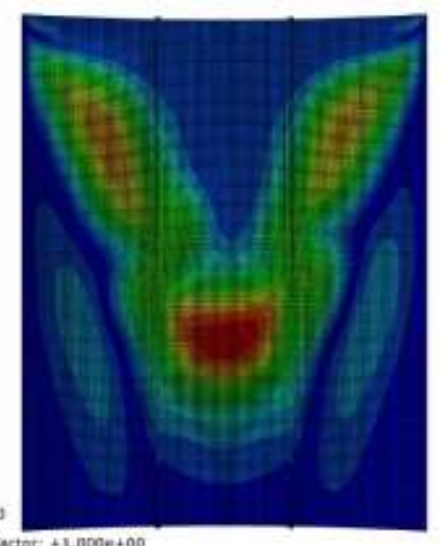

Figure 12: Post - Buckling Behaviour of the panel P3H2

In Table 5, the initial buckling load and ultimate load of the panel without and with stiffener compared for various stiffener. The panel without stiffener has lower buckling load and ultimate load when compare to the panel with stiffener 


\section{International Journal of Innovative Research in \\ Electrical, Electronics, Instrumentation and Control Engineering}

Vol. 9, Issue 10, October 2021

DOI: 10.17148/IJIREEICE.2021.91019

Table 5: Comparison of the panel with various stiffener shapes

\begin{tabular}{|l|l|l|}
\hline PANEL ID & $\begin{array}{l}\text { INITIAL BUCKLING LOAD } \\
(\mathrm{kN})\end{array}$ & ULTIMATE LOAD $(\mathrm{kN})$ \\
\hline P2 & 95.68 & 166.86 \\
\hline P2I2 & 99.53 & 218.76 \\
\hline P2J2 & 99.03 & 217.25 \\
\hline P2H2 & 99.52 & 243.59 \\
\hline P3 & 74.72 & 122.01 \\
\hline P3I2 & 78.141 & 479.77 \\
\hline P3J2 & 77.75 & 453.82 \\
\hline P3H2 & 78.14 & 488.89 \\
\hline
\end{tabular}

By plotting the load-shortening curves for panels with panel radius $1000 \mathrm{~mm}$ and $1500 \mathrm{~mm}$ are shown in Figures 13 and 14 respectively describes the buckling and post buckling behaviour of the panel without stiffener and panel with various stiffeners. By investigating various shape; I- stiffener has high buckling strength compared to the other stiffener shapes and the hat stiffener has high ultimate load compared to the other stiffener shapes.

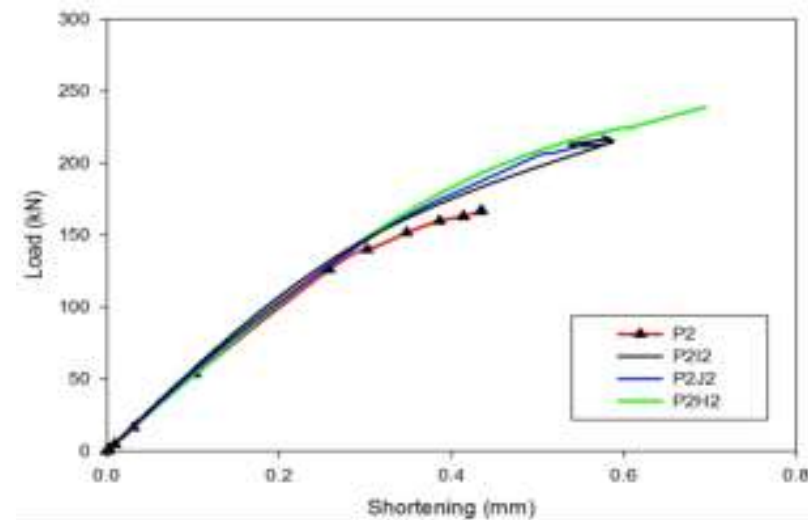

Figure 13: Load-shortening curves of panel P2I2, P2J2, and P2H2

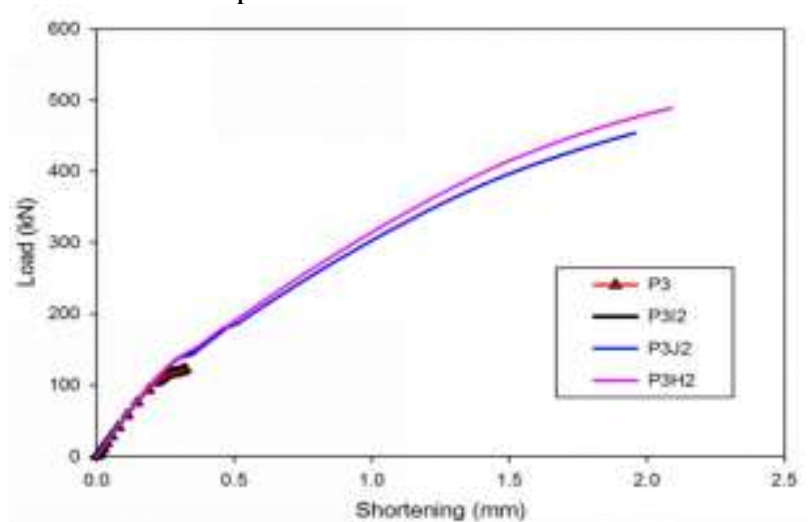

P2, Figure 14: Load-shortening curves of panel P3, P3I2, P3J2, and P3H2

\section{CONCLUSION}

Buckling is the most common failure in the thin-walled structures. In order to improve buckling strength, various techniques are emerging. Buckling strength is influenced by various parameters such as curvature of the panel, various shapes of the stiffener, number of stiffeners, the thickness of the stiffened panel and cut-outs. In this research work, numerical investigations were carried out on 10 models of the stiffened panel using commercial finite element software Abaqus v6.14 has been used on various panel radius and types of the stiffener under uniaxial compression load. To predict the critical buckling load and mode shape for the first buckling modes of the stiffened panel have been obtained by the Linear Eigen Value Extraction method. The failure load of the stiffened curved panel after buckling was predicted by using STATIC Riks (arc length) method. Initial geometrical imperfections and nonlinearities of the materials were considered for better results. The exactness of the code used in this research was verified by carrying out various confirmation studies. The outcome obtained from the validation studies conducted were agreeable. The numerical results obtained are qualitatively presented using displacement contours of the buckling and post-buckling behaviours and the quantitative presentation of important parameters such as ultimate load is carried out using load- shortening plots.

- $\quad$ To investigate the effect of panel radius of the stiffened panel the buckling load and ultimate load are obtained from the load- shortening plots. When the panel radius is increased, the buckling load and ultimate load are decreases constantly. The curvature of the panel resists the compressive load leads to carry higher loads.

- $\quad$ The effect of various type of stiffener on the buckling load and ultimate load are investigated by using the load shortenings plots. The stiffened panel with Hat-shape has a higher load carrying capacity compared to the other shapes (I-Shape and J-Shape). The variation in the buckling load and ultimate loads are very small for various stiffeners.

- The buckling load and the ultimate load obtained by using load-shortenings plots are used to investigate the effect in the stiffened panel. 


\title{
International Journal of Innovative Research in Electrical, Electronics, Instrumentation and Control Engineering
}

\author{
Vol. 9, Issue 10, October 2021
}

\section{DOI: $10.17148 /$ IJIREEICE.2021.91019 \\ REFERENCES}

1. A. Karrech, M. Elchalakani, M. Attar, and A. C. Seibi, "Buckling and post-buckling analysis of geometrically non-linear composite plates exhibiting large initial imperfections," Compos. Struct., 2017, doi: 10.1016/j.compstruct.2017.04.029.

2. R. Bai, Z. Lei, X. Wei, W. Tao, and C. Yan, "Numerical and experimental study of dynamic buckling behavior of a J-stiffened composite panel under in-plane shear," Compos. Struct., 2017, doi: 10.1016/j.compstruct.2017.01.022.

3. A. Castriota, V. Dattoma, B. Gambino, R. Nobile, and A. Saponaro, "Experimental behavior of a CFRP damaged panel subjected to compressive stress," in Procedia Structural Integrity, Jan. 2019, vol. 24, pp. 279-288, doi: 10.1016/j.prostr.2020.02.025.

4. Y. Feng, Y. He, H. Zhang, X. Tan, T. An, and J. Zheng, "Effect of fatigue loading on impact damage and buckling / post-buckling behaviors of stiffened composite panels under axial compression," Compos. Struct., 2016, doi: 10.1016/j.compstruct.2016.12.069.

5. N. Kharghani and C. Guedes Soares, "Experimental, numerical and analytical study of buckling of rectangular composite laminates," Eur. J. Mech. A/Solids, vol. 79, p. 103869, Jan. 2020, doi: 10.1016/j.euromechsol.2019.103869.

6. A. D. Martins and N. Silvestre, "Modal analysis and imperfection sensitivity of the post-buckling behaviour of cylindrical steel panels under in-plane bending,” Eng. Struct., vol. 207, p. 110127, Mar. 2020, doi: 10.1016/j.engstruct.2019.110127.

7. T. Manco, J. P. Martins, C. Rigueiro, and L. Simões da Silva, "Semi-analytical orthotropic model for the prediction of the post-buckling behaviour of stiffened cylindrically curved steel panels under uniaxial compression,” Comput. Struct., vol. 211, pp. 27-42, Jan. 2019, doi: 10.1016/j.compstruc.2018.08.015.

8. Y. SU, Z. GUAN, X. WANG, Z. LI, J. GUO, and Y. HUANG, "Buckling and post-buckling behavior of titanium alloy stiffened panels under shear load," Chinese J. Aeronaut., vol. 32, no. 3, pp. 619-626, 2019, doi: 10.1016/j.cja.2018.09.007.

9. K. L. Tran, C. Douthe, K. Sab, J. Dallot, and L. Davaine, "Buckling of stiffened curved panels under uniform axial compression,” J. Constr. Steel Res., vol. 103, pp. 140-147, 2014, doi: 10.1016/j.jcsr.2014.07.004.

10. Y. Ye, W. Zhu, J. Jiang, Q. Xu, and Y. Ke, "Computational modelling of postbuckling behavior of composite T-stiffened panels with different bonding methods," Compos. Part B Eng., vol. 166, pp. 247-256, Jun. 2019, doi: 10.1016/j.compositesb.2018.11.137.

11. R. Bai et al., "Experimental study on compressive behavior of I-stiffened CFRP panel using fringe projection profilometry," Ocean Eng., vol. 160, no. June 2019, pp. 382-388, 2018, doi: 10.1016/j.oceaneng.2018.04.085.

12. L. Zhao et al., "A post-buckling compressive o analysis framework for composite stiffened panels considering intra-, inter-laminar damage and stiffener debonding," Results Phys., vol. 13, no. March, p. 102205, 2019, doi: 10.1016/j.rinp.2019.102205.

13. S. Piculin and P. Može, "Stability behaviour of stiffened curved plates subjected to pure compression," Thin-Walled Struct., vol. 159, p. 107313, Feb. 2021, doi: 10.1016/j.tws.2020.107313.

14. N. R. Kolanu, G. Raju, and M. Ramji, "Experimental and numerical studies on the buckling and post-buckling behavior of single bladestiffened CFRP panels," Compos. Struct., vol. 196, pp. 135-154, 2018, doi: 10.1016/j.compstruct.2018.05.015.

15. S. N. Masood, R. Vishakh, S. R. Viswamurthy, and K. M. Gaddikeri, "Influence of stiffener configuration on post-buckled response of composite panels with impact damages," vol. 194, no. March, pp. 433-444, 2018, doi: 10.1016/j.compstruct.2018.04.005.

16. Mo, Y, Ge, D \& Zhou, J, 'Experiment and analysis of hat-stringer-stiffened composite curved panels under axial compression', Composite Structures, vol. 123, pp. 150-60, 2015.

17. Zhu, S, Yan, J, Chen, Z, Tong, M \& Wang, Y, 'Effect of the stiffener stiffness on the buckling and post-buckling behaviour of stiffened composite panels - Experimental investigation', Composite Structures, vol. 120, pp. 334-45, 2015. 